\title{
Nonuniform Action Potential Durations at Different Sites in Canine Left Ventricle
}

\author{
Souichiro Sekrya, M.D.,* Santa Ichikawa, M.D.,* \\ Takeshi Tsutsumi, M.D., ${ }^{* *}$ and Kenichi Harumi, M.D.**
}

\section{Summary}

We studied the action potential duration (APD) of isolated ventricular muscle fibers. Action potentials were recorded from four different sites (endocardium and epicardium at the apex and the base) in the canine left ventricle by microelectrode techniques. Action potentials from endocardial and corresponding epicardial specimens, and the differential potential between them were recorded simultaneously. The APDs at $60 \%$ and $90 \%$ repolarization $\left(\mathrm{APD}_{60}\right.$ and $\mathrm{APD}_{90}$ ) were measured during superfusion with normal $\left(\mathrm{K}^{+}=2.7 \mathrm{mM}\right)$ and altered $\left(\mathrm{K}^{+}=5.4 \mathrm{mM}\right)$ Tyrode's solutions. Results were: 1) the distributions of APDs agreed with previous descriptions from in vivo studies; 2) endo-epicardial APD gradients were different between the apex and the base, and apicobasal APD gradients were different between endocardium and epicardium; 3) the shapes of the differential potentials in normal and altered Tyrode's solution were similar to the electrocardiographic $\mathrm{T}$ wave form in normal and in mild hyperkalemia. It was concluded that nonhomogeneous APDs may be due to the inherent characteristics of cardiac muscle and the nonuniform endo-epicardial APD gradient helps to account for the genesis of the electrocardiographic $\mathbf{T}$ wave form.

\section{Additional Indexing Words:}

Action potential duration Hyperkalemia $\mathrm{T}$ wave Endoepicardial gradient Apico-basal gradient

$\mathrm{T}$ HE direction and shape of the $\mathrm{T}$ wave in the electrocardiogram (EGG) is usually explained by differences in the depolarization and repolarization sequences in the ventricle. ${ }^{1-3)}$ Present knowledge of the recovery properties is based on in vivo measurements of functional refractory periods, ${ }^{4)-6)}$

* From the Department of Physiology, Showa Univcrsity School of Medicine, Tokyo and ** Division of Cardiology, Showa University Fujigaoka Hospital, Yokohama.

Address for reprint: Souichiro Sekiya, M.D., Division of Cardiology, Showa University Fujigaoka Hospital, 1-30 Fujigaoka, Midori-ku, Yokohama 227, Japan,

Received for publication June 28, 1983. 
epicardial and intramural potential distributions," and repolarization durations. ${ }^{8)}$ Studies in vitro ${ }^{9 / 12}$ indicate that the durations of transmembrane action potentials of the endocardial cells are longer than those of the epicardial cells. These data have been used to explain the genesis of the $T$ wave in ECG, but, to our knowledge, there has been no in vitro study which compares systematically the durational action potentials in multiple regions of the same ventricle.

It is generally agreed that a common ECG finding of mild hyperkalemia is a tall, peaked $T$ wave. Simultaneous recordings of the EGG and epicardial action potential show a close relationship between the shape of the action potential and the $T$ wave form in ECG, and the steeper downslope of action potential accounts for the $T$ wave in hyperkalemia. ${ }^{15}$ Recently, it has been pointed out that electrophysiological responses of endocardial and epicardial cells were different during both repetitive activity ${ }^{11)}$ and simulated conditions of ischemia. ${ }^{12}$

In the present study, action potentials were recorded from two different regions (apex and base) of the endocardium and epicardium of 4 canine left ventricular specimens and compared during the superfusion of normal $\left(2.7 \mathrm{mM} \mathrm{K}^{+}\right)$and altered $\left(5.4 \mathrm{mM} \mathrm{K}^{+}\right)$Tyrode's solutions. Nonhomogeneous action potential durations in normal Tyrode's solution and nonuniform shortening of action potential durations in the altered solution were evaluated to help explain the $\mathrm{T}$ wave form in normal conditions and in mild hyperkalemia.

\section{Methods}

Twelve mongrel adult dogs $(8-15 \mathrm{Kg})$ were anesthetized with sodium pentobarbital $(30 \mathrm{mg} / \mathrm{Kg}$, iv). The chest wall was opened by a left thoracotomy. The heart was removed and placed immediately in cool oxygenated Tyrode's solution of the following composition $(\mathrm{mM}): \mathrm{NaCl}, 137.0 ; \mathrm{NaH}_{2} \mathrm{PO}_{4}$, 1.8; $\mathrm{NaHCO}_{2}, 12.0 ; \mathrm{MgCl}_{2}, 0.5 ; \mathrm{KCl}, 2.7 ; \mathrm{CaCl}_{2}, 2.7 ;$ glucose, $5.5(\mathrm{pH}$ 7.2-7.3). Two $10 \times 10 \mathrm{~mm}$ rectangular blocks of myocardium were dissected; one from the apical and one from the basal region (Fig. 1). Each block was divided in half by an incision through the midmyocardium, and sliced to 2-4 $\mathrm{mm}$ thickness for comparative endocardial and epicardial studies. The four resulting specimens were mounted with small steel pins on the wax bottom of a lucite chamber with their respective endocardial and epicardial surfaces upward. The chamber had an effective volume of $20 \mathrm{ml}$. The specimens were superfused at a rate of $10 \mathrm{ml} / \mathrm{min}$ with warm $\left(36.5-36.8^{\circ} \mathrm{C}\right)$ Tyrode's solution gassed with $95 \% \mathrm{O}_{2}-5 \% \mathrm{CO}_{2}$. 


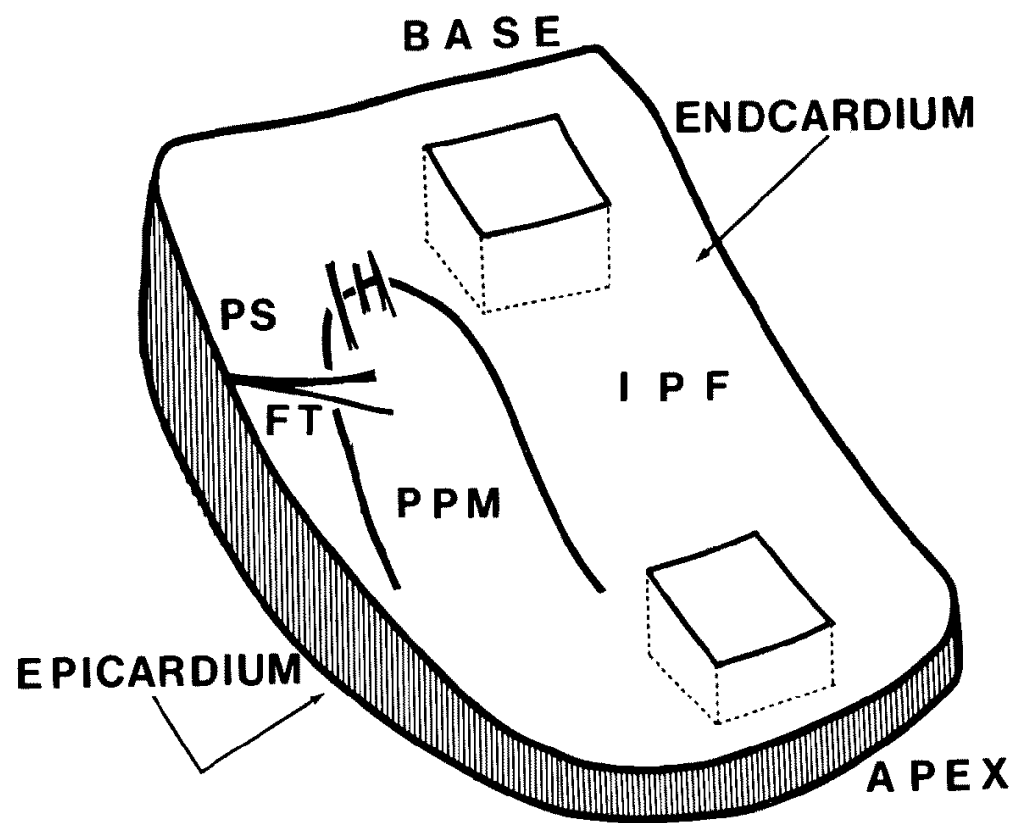

Fig. 1. Schematic representation of part of left ventricular free wall. The left ventricle was opened through interventricular septum. Two blocks indicate the approximate sites excised from the apex and the base. These were sliced to make two pairs of specimens (endocardial and corresponding epicardial specimens). $\mathrm{PS}=$ paraseptal free wall; $\mathrm{FT}=$ false tendon; $\mathrm{PPM}=$ posterior papillary muscle; IPF = interpapillary free wall.

Each specimen was stimulated independently at $1,000 \mathrm{msec}$ intervals through bipolar Teflon coated $\mathrm{Ag}-\mathrm{AgCl}$ electrodes. Stimuli were rectangular pulses of 1-3 msec duration and the current intensity was 1.5 times the diastolic threshold.

Action potentials were recorded with $3 \mathrm{M} \mathrm{KGl-filled} \mathrm{glass} \mathrm{microelectrodes}$ (the tip resistance, $15-30 \mathrm{M} \Omega$; tip potential, less than $2 \mathrm{mV}$ ) connected through $\mathrm{Ag}-\mathrm{AgCl}$ junctions to a high input impedance amplifier with input capacitance neutralization (model 750, WP Instruments, Inc). The recordings were displayed on an oscilloscope (VC-9, Nihon Kohden, Co) and photographed with a Polaroid camera.

Action potentials from endocardial and epicardial fibers, and the differential potentials between them, were simultaneously recorded and displayed. Action potentials of Purkinje fibers were sometimes recorded from the subendocardial layer, particularly in the apical specimen. The tip of the microelectrode was advanced through the subendocardium and action potentials were recorded from underlying fibers. Action potential characteristics of ventricular fibers were discriminated from those of Purkinje fibers by previously 
described criteria. ${ }^{16), 17)}$

After 45-60 min of equilibration in normal Tyrode's solution, the specimens were superfused with altered Tyrode's solution, which differed from the normal Tyrode's solution only in its $5.4 \mathrm{mM} \mathrm{KCl}$ content.

Action potential characteristics which were measured in the two solutions were: resting membrane potential (RMP), action potential amplitude (APA), and action potential durations at $60 \%$ and $90 \%$ of repolarization $\left(\mathrm{APD}_{60}\right.$ and $\left.\mathrm{APD}_{90}\right)$. The endo-epicardial $\mathrm{APD}$ gradient, the difference between endocardial and epicardial APDs; and the apico-basal APD gradient, the difference between APDs from the apex and base were compared in both solutions. In addition, the ratio of averaged APDs with normal Tyrode's solution to those with altered Tyrode's solution (shortening ratio) was measured. Statistical analysis was performed using Student's t-test for paired or unpaired data.

\section{Results}

Normal Tyrode's solution:

The RMPs and APAs from four different specimens are summarized in Table I. The RMPs of the four specimens were not significantly different, but APAs of the epicardial fibers were significantly lower than those of corresponding endocardial fibers in both the apex and the base.

Fig. 2 shows representative action potentials recorded from four sites in one dog heart. The tracing below each pair of action potentials shows the differential potential between the respective endo- and epicardial action potentials. Since the action potentials of endocardial fibers are substantially longer than those of epicardial fibers, the differential potentials are positive

Table I. RMP and APA in Normal and Altered Tyrode's Solution for 12 Dogs

\begin{tabular}{c|c|c|c|c}
\hline \multirow{2}{*}{} & \multicolumn{2}{|c|}{ END } & \multicolumn{2}{c}{ EPI } \\
\cline { 2 - 5 } & Normal $(\mathrm{mV})$ & Altered $(\mathrm{mV})$ & Normal $(\mathrm{mV})$ & Altered $(\mathrm{mV})$ \\
\hline (APEX) & & & & \\
RMP & $-89.3 \pm 2.1^{*}$ & $-78.8 \pm 2.9$ & $-88.0 \pm 3.6^{*}$ & $-76.5 \pm 3.0$ \\
APA & $114.4 \pm 3.5^{* \dagger}$ & $107.1 \pm 2.8 \dagger$ & $106.3 \pm 4.4^{* \dagger}$ & $95.7 \pm 3.3$ \\
\hline BASE) & & & & \\
RMP & $-89.4 \pm 2.6^{*}$ & $-79.6 \pm 2.4$ & $-88.7 \pm 3.6^{*}$ & $-76.2 \pm 2.7$ \\
APA & $114.2 \pm 5.5^{* \dagger}$ & $106.8 \pm 5.8 \dagger$ & $105.6 \pm 3.7 * \dagger$ & $95.8 \pm 4.4$
\end{tabular}

Data are expressed as mean \pm SD.

* $\mathrm{p}<0.01$ : significant difference between normal and altered Tyrode's solution.

$+\mathrm{p}<0.01$ : significant difference between endocardium and epicardium. 

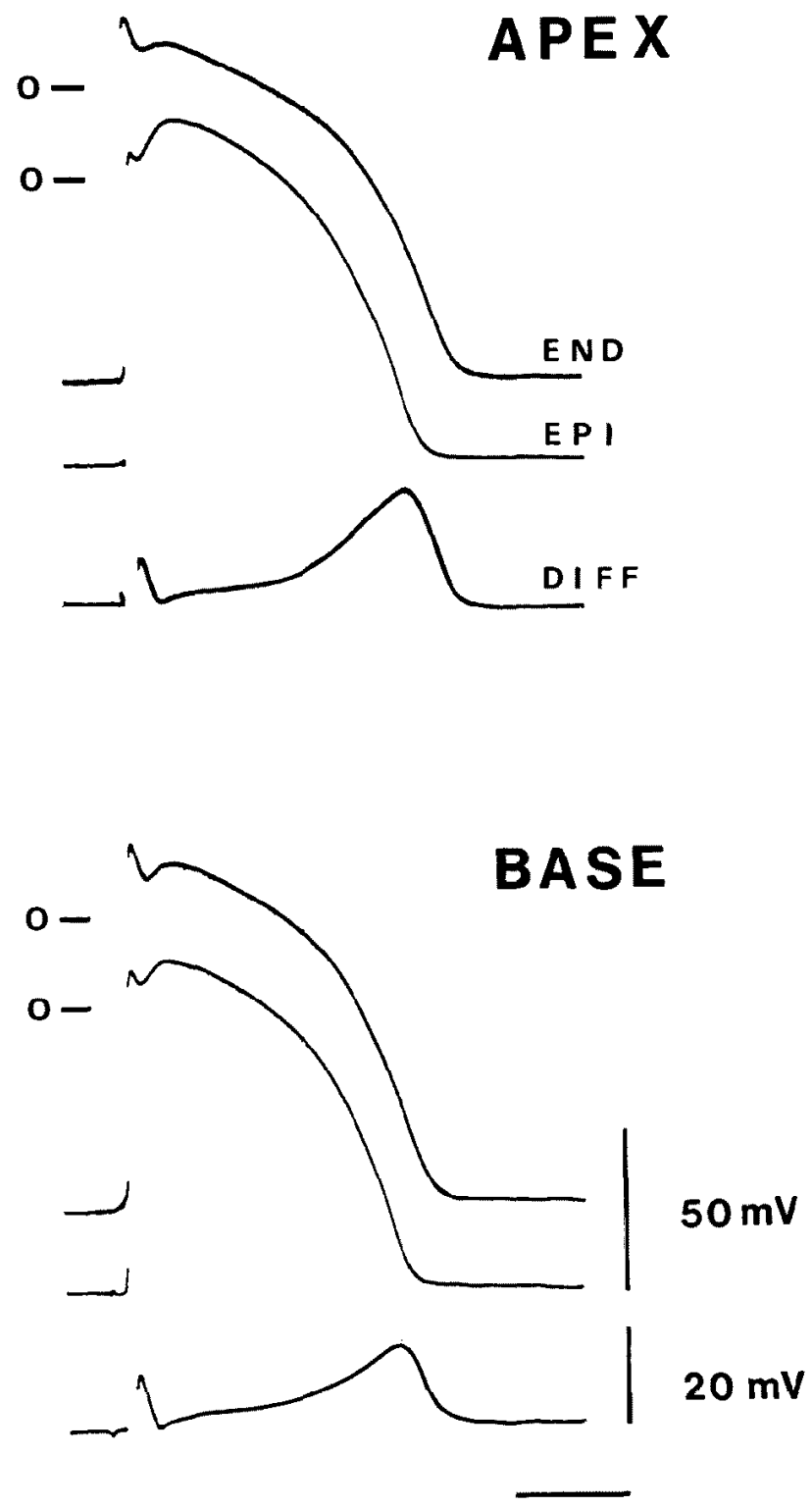

$100 \mathrm{msec}$

Fig. 2. Representative simultaneous recordings of action potentials from the apex (upper) and the base (lower) in nomal Tyrode's solution. In each panel, the upper trace is the endocardial action potential (END), the middle is the epicardial action potential (EPI) and the lower is the differential recording between endocardial and epicardial action potentials (DIFF). In each region, the epicardial fiber was activated several msec later than the endocardial fiber. 
Table II. APD 60 and $A P D_{90}$ in Normal and Altered Tyrode's Solution for 12 Dogs

\begin{tabular}{|c|c|c|c|c|}
\hline & \multicolumn{2}{|c|}{ APEX } & \multicolumn{2}{|c|}{ BASE } \\
\hline & $\mathrm{APD}_{60}$ (msec) & $\mathrm{APD}_{90}$ (msec) & $\mathrm{APD}_{60}$ (msec) & $\mathrm{APD}_{80}(\mathrm{msec})$ \\
\hline \multicolumn{5}{|l|}{ (END) } \\
\hline Normal & $217.1 \pm 8.5^{*+8}$ & $261.2 \pm 9.1 *+8$ & $205.3 \pm 12.4^{* \dagger}$ & $243.7 \pm 11.6^{*} \dagger$ \\
\hline Altered & $199.8 \pm 4.8+\$$ & $229.3 \pm 6.6+8$ & $191.1 \pm 9.8 \dagger$ & $222.4 \pm 8.6 t$ \\
\hline $\begin{array}{l}\text { Absolutc } \\
\text { Shortening }\end{array}$ & $-17.3 \pm 5.2 \dagger$ & $-31.9 \pm 7.2+\S$ & $-14.2 \pm 6.4$ & $-21.3 \pm 6.1$ \\
\hline $\begin{array}{l}\text { Shortening } \\
\text { Ratio }(\%)\end{array}$ & -8.0 & -12.2 & -6.9 & -8.7 \\
\hline \multicolumn{5}{|l|}{ (EPI) } \\
\hline Normal & $191.2 \pm 4.8^{*}$ & $221.8 \pm 5.7 * \S$ & $184.0 \pm 7.2^{*}$ & $213.9 \pm 6.3^{*}$ \\
\hline Altered & $179.5 \pm 6.48$ & $199.1 \pm 4.7 \S$ & $170.0 \pm 7.2$ & $191.3 \pm 6.7$ \\
\hline $\begin{array}{l}\text { Absolute } \\
\text { Shortening }\end{array}$ & $-11.7 \pm 4.2$ & $-22.7 \pm 4.1$ & $-14.0 \pm 6.1$ & $-22.6 \pm 6.0$ \\
\hline $\begin{array}{l}\text { Shortening } \\
\text { Ratio }(\%)\end{array}$ & -6.1 & -10.2 & -7.6 & -10.6 \\
\hline
\end{tabular}

Data are expressed as mean $\pm \mathrm{SD}$.

* $p<0.01$ : significant difference between normal and altered Tyrode's solution.

$+\mathrm{p}<0.01$ : significant difference between endocardium and epicardium.

$\$ p<0.01$ : significant difference between apex and base.

Table III. Endo-epicardial (END-EPI) and Apico-basal (APEX-BASE) APD Gradients in Normal and Altered Tyrode's Solution for 12 Dogs

\begin{tabular}{c|c|c|c|c}
\hline \multirow{2}{*}{} & \multicolumn{2}{|c|}{ APD $_{60}$} & \multicolumn{2}{c}{ APD $_{90}$} \\
\cline { 2 - 5 } & Normal (msec) & Altered (msec) & Normal (msec) & Altered (msec) \\
\hline (END-EPI) & & & & \\
APEX & $25.9 \pm 8.4^{*}$ & $20.3 \pm 6.2$ & $39.4 \pm 8.8 * 8$ & $30.2 \pm 6.3$ \\
BASE & $21.3 \pm 6.8$ & $21.1 \pm 4.7$ & $29.8 \pm 8.4$ & $31.1 \pm 6.4$ \\
(APEX-BASE) & & & & \\
END & $11.8 \pm 6.7^{*}$ & $8.7 \pm 2.7$ & $17.5 \pm 6.2 * \dagger$ & $6.9 \pm 3.6$ \\
EPI & $7.2 \pm 2.8$ & $9.5 \pm 3.2$ & $7.9 \pm 2.9$ & $7.8 \pm 2.1$
\end{tabular}

Data are expressed as mean $\pm \mathrm{SD}$.

* $p<0.01$ : significant difference between normal and altered Tyrode's solution.

$\$ \mathrm{p}<0.01$ : significant difference between apex and base.

$\uparrow \mathrm{p}<0.01$ : significant difference between endocardium and epicardium.

upward in both regions. The $\mathrm{APD}_{60}$ and $\mathrm{APD}_{90}$ values are summarized for all experiments in Table II. In both regions, the $\mathrm{APD}_{60}$ and $\mathrm{APD}_{90}$ were both significantly longer in the endocardium than in the corresponding epicardium. In both endocardium and epicardium, the APDs at the apex were significantly longer than those at the base. The endo-epicardial $\mathrm{APD}_{60}$ and $\mathrm{APD}_{90}$ gradients were significantly greater at the apex than at the base, and 
the apico-basal $\mathrm{APD}_{60}$ and $\mathrm{APD}_{90}$ gradients were significantly greater in the endocardium than in the epicardium; the actual values are shown in Table III. The longest APD was found in apical endocardial fibers and the shortest was in basal epicardial fibers. The differences between the longest and
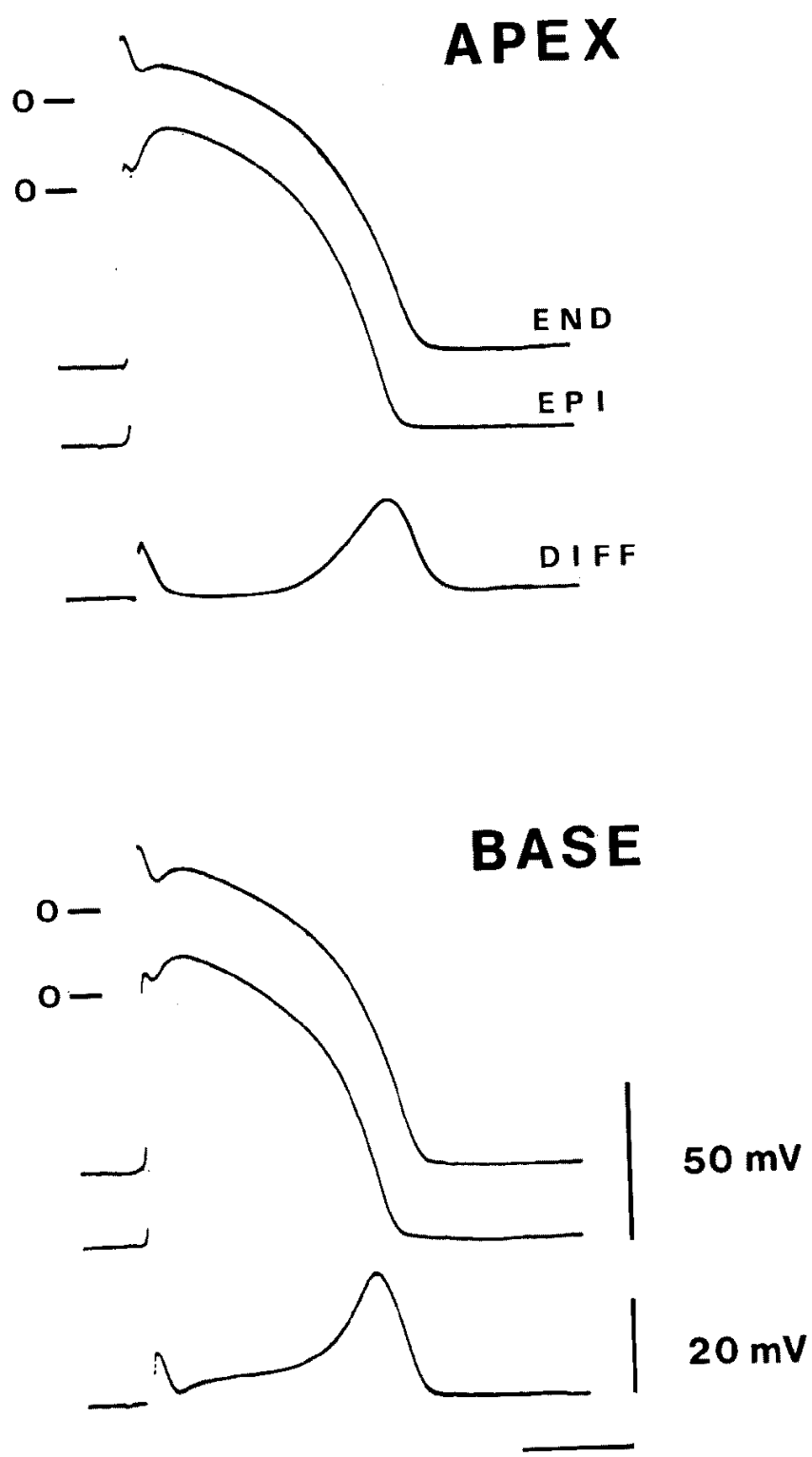

$100 \mathrm{msec}$

Fig. 3. Representative simultaneous recordings of action potentials in altered Tyrode's solution. Recordings were from the same fibers from which Fig. 2 was obtained. 
shortest $\mathrm{APD}_{60}$ was $33.1 \pm 7.8 \mathrm{msec}$; for the $\mathrm{APD}_{90}$, it was $47.3 \pm 8.2 \mathrm{msec}$.

Altered Tyrode's solution:

During superfusion with altered Tyrode's solution, the RMPs depolarized 10 to $12 \mathrm{mV}$. The RMPs of epicardial fibers tended to be slightly smaller than those of endocardial fibers, but the difference was not significant (Table I).

Increasing $\mathrm{K}^{+}$concentration from 2.7 to $5.4 \mathrm{mM}$ shortened the action potentials in both the endocardial and epicardial fibers, but not uniformly (Table II). In all sites, the $\mathrm{APD}_{90}$ shortened more than the $\mathrm{APD}_{60}$ both relatively and absolutely (Table II), so that the downslope of action potential became steeper. At the apex, the absolute values were greater in the endocardium than in the epicardium, but, because of the greater initial length, the ratios of shortening were similar. On the other hand, the shortening ratios were greater in the epicardium than in the endocardium, especially the $\mathrm{APD}_{90}$. However, the absolute values were similar. Fig. 3 shows representative action potentials and differential records during superfusion with altered Tyrode's solution. The peak of the differential wave was higher than in normal Tyrode's solution at the base, but not at the apex. Other endocardial-epicardial and apex-base relations remained the same as in normal Tyrode's solution. The endo-epicardial APD gradient was reduced at the apex and unchanged at the base, compared to normal Tyrode's solution, and the apico-basal APD gradient was reduced in the endocardium and unchanged in the epicardium (Table III). Although the APD shortening was greatest in the apical endocardial fibers, the longest APD was found at this site and the shortest was found in basal epicardial fibers. The differences were $29.8 \pm 6.8 \mathrm{msec}$ for the $\mathrm{APD}_{60}$ and $38.0 \pm 6.6 \mathrm{msec}$ for the $\mathrm{APD}_{90}$. These differences were shorter than those observed in normal Tyrode's solution.

\section{Disaussion}

The present study demonstrates that 1) the endo-epicardial APD gradients differ from the apex to the base, 2) the effects of altered Tyrode's solution on endo-epicardial APD gradient were nonuniform, and 3) the shapes of the differential potentials between the endocardial and epicardial action potentials during superfusion of normal and altered Tyrode's solutions were similar to the ECG $\mathrm{T}$ wave forms. These agree with observations made in in situ studies. ${ }^{3)-8 \text { ) }}$

Endocardial muscle fibers may have different intrinsic electrophysiological properties than epicardial muscle fibers.9 ${ }^{9)-14}$ Moore et al ${ }^{9)}$ commented 
that the epicardium had considerable connective tissue on its surface that may act as a diffusion barrier, and that epicardial cells had a lower RMP than endocardial cells. But in both the present and previous studies, ${ }^{10), 12)-14)}$ no significant difference was found between endocardial and epicardial RMPs. Recently, Watanabe et al ${ }^{18)}$ observed different APDs in isolated ventricular myocytes and tissue of the rat, and concluded that the differences were due to heterogeneity. However, there are marked differences between the action potential configurations observed in ventricular muscle fibers of the rat and other mammalian hearts. ${ }^{16}$ ) In addition, the responses during repetitive activity differ between endocardial and epicardial cells, and may depend on differences in Na-K pump activity. ${ }^{11}$ Other possibilities are the differences in intracellular potassium concentrations between endocardial and epicardial cells $^{19)}$ and fluctuations in the extracellular potassium level. ${ }^{20)}$

Mechanisms underlying the differences between the APDs have not been fully defined. The present observation that the shortening rates of APDs are different during superfusion with altered Tyrode's solution suggests that the effects of the potassium ion may be different in endocardial and epicardial fibers. The nonuniform shortening of APDs may be partly explained by three considerations. First, responses of endocardial and epicardial fibers are different under identical conditions of ischemia, and endocardial fibers show responses intermediate between Purkinje fibers and epicardial fibers. ${ }^{12)}$ Second, there is an electrotonic interaction between action potentials from ventricular muscle and Purkinje fibers. The action potential durations in ventricular muscle fibers are longer for richly supplied Purkinje fibers than for poorly supplied fibers, ${ }^{17)}$ and Purkinje fibers are not observed in the outer third of the ventricular wall. ${ }^{19}$ Finally, a marked shortening of action potentials associated with a potassium concentration increase has been demonstrated in Purkinje fibers compared to ventricular fibers. ${ }^{21)}$

Although it may not be obvious that these endo-epicardial and apicobasal APD gradients are responsible for the polarity of the $T$ wave, a nonuniform shortening of the APD can explain the $\mathrm{T}$ wave changes observed in the electrocardiogram. Hecht ${ }^{22}$ ) commented that if the downslope of the action potential changes while the ventricular gradient remains unaltered, the magnitude of the $\mathrm{T}$ wave will change. In the body surface electrocardiogram, the peak T wave is best seen in leads II and III, and the precordial lead. ${ }^{23)}$ In the present study, the downslope of the action potential was sharply associated with a potassium increase. The shortening ratio of $\mathrm{APD}_{90}$ was greater at the epicardium than at the endocardium, but the absolute difference between APDs remained the same as in normal Tyrode's solution. Thus, the differential potential became higher at the base. These observations 
partly account for the $T$ wave change seen in the precordial lead. On the other hand, at the apex, the downslope of the action potential was sharp and the shortening ratio of APD was similar in the endocardium and epicardium. However, the absolute APD difference diminished in comparison with normal Tyrode's solution, where the peak of the differential potential did not increase.

The $\mathrm{T}$ wave in leads II and III may be caused by both endo-epicardial gradient and the apico-basal gradient. ${ }^{31,19}$ Since an increased potassium concentration reduced the endo-epicardial APD gradient and the apico-basal APD gradient, the shape of the $T$ wave in leads II and III, associated with mild hyperkalemia, was not merely due to changes such as the sharp downslope of the action potential; it also depended on the different potential in the present study.

\section{Aaknowledgment}

We thank Dr. Albert Simpson, Showa University, for reading the manuscript.

\section{REFERENCES}

1. Wilson FN, MacLeod AG, Barker PS: The $T$ deflection of the electrocardiogram. Trans Assn Am Physicians 46: 29, 1931

2. Harumi K, Burgess MJ, Abildskov JA: A theoretic model of $T$ wave. Circulation 34: 657 , 1966

3. Burgess $\mathrm{MJ}$ : Relation of ventricular repolarization to electrocardiographic $\mathrm{T}$ wave-form and arrhythmia vulnerability. Am J Physiol 236: H391, 1979

4. Van Dam R, Durrer D: Experimental study on the intramural distribution of the excitability cycle and on the form of the epicardial $T$ wave in the dog heart in situ. Am Heart J 61: 537,1961

5. Burgess MJ, Green LS, Millar K, Wyatt R, Abildskov JA: The sequence of normal ventricular recovery. Am Heart J 84: 660, 1972

6. Abildskov JA: The sequence of normal recovery of excitability in the dog heart. Girculation 52: 442, 1975

7. Spach MS, Barr RC: Ventricular intramural and epicardial potential distributions during ventricular activation and repolarization in the intact dog. Circulat Res 37: 243, 1975

8. Tsutsumi T, Wyatt RL, Abildskov JA: Effects of hyperkalemia on local changes of repolarization duration in canine left ventricle. J Electrocardiol 16; 1, 1983

9. Moore EN, Preston JB, Moe GK: Durations of transmembrane action potentials and functional refractory periods of canine false tendon and ventricular myocardium. Circulat Res 17: 259,1965

10. Solberg LE, Singer DH, Ten Eick RE, Duffin EG Jr: Glass microelectrode studies on intramural papillary muscle cells. Circulat Res 34: 783, 1974

11. Cohen I, Giles W, Noble D: Gellular basis for the $\mathbf{T}$ wave of the electrocardiogram. Nature 262: 657,1976

12. Gilmour RF, Zipes DP: Different electrophysiological responses of canine endocardium and epicardium to combined hyperkalemia, hypoxia, and acidosis. Circulat Res 46: 814, 1980 
13. Aronson RS: Characteristics of action potentials of hypertrophied myocardium from rats with renal hypertension. Circulat Res 47: 443, 1980

14. Keung ECH, Aronson RS: Non-uniformal electrophysiological properties and electrotonic interaction in hypertrophied rat myocardium. Circulat Res 49: 150, 1981

15. Surawicz B: Relationship between elcctrocardiogram and clcctrolytes. Am Heart J 73: 814,1967

16. Hoffman BF, Cranefield PF: Electrophysiology of the Heart, McGraw Hill, New York, 1960

17. Mendez G, Mueller WJ, Merideth J, Moc GK: Interaction of transmembrane potentials in canine Purkinje fibers and at Purkinje fiber-muscle junctions. Circulat Res 24: 361, 1969

18. Watanabe T, Delbridge LM, Bustamante JO, McDonald TF: Heterogeneity of the action potential in isolated rat ventricular myocytes and tissue. Circulat Res 52: 280, 1983

19. Lepcschkin E: Role of myocardial temperature, electrolyte and stress gradients in the genesis of the normal $\mathrm{T}$ wave, in Advance in Electrocardiography, ed by Schlant RC, Hurst JW, Grune and Stratton Inc, New York, p 339, 1976

20. Cohen $\mathrm{I}$, Kline $\mathrm{R}: \mathrm{K}^{+}$functions in the extracellular spaces of cardiac muscle. Circulat Res 50: 1, 1982

21. Carmeliet E, Vereecke J: Electrogenesis of the action potential and automaticity. in Handbook of Physiology, Section 2 (The Cardiovascular System), ed by Berne RM, Sperelakis N, Geiger SR, American Physiological Society, Bethesda, p 269, I979

22. Hecht $\mathbf{H H}$ : Some observations and theories concerning the electrical behavior of heart muscle. Am J Med 30: 720, 1961

23. Chung KE: Electrocardiography, 2nd Ed, Harper and Row, Hagerstown, 1980 